\title{
Research on College Students' autonomous learning elements in computer network environment
}

\author{
$\mathrm{XU}$ Yiqun ${ }^{1, \text { a }}$ \\ ${ }^{1}$ Jilin Business and Technology College, Changchun 130000, China \\ aemail: xuyiqun@163.com
}

Keywords: Computer; network; autonomous learning factors; research methods

\begin{abstract}
In this paper, under the computer network environment of college students as the research object, in the College English curriculum requirements "(for Trial Implementation) under the guidance of related theory, combined with the constructivist learning theory and the theory of autonomous learning and college students' autonomous learning of several elements, such as learning motivation, the learning methods, learning plan, reflective learning and research. Experience in the period of a year the Ministry of education reform process, with the aid of in the comparative study, questionnaire survey, statistical analysis and other research methods, college students self learning under the network environment of the relevant factors predisposing, culture and combination is proposed the corresponding countermeasures, and how to fully develop essential advantage under the network environment, to mobilize the positive factors, improve the effectiveness of teaching puts forward personal opinions.
\end{abstract}

\section{Introduction}

The reform of College English Teaching in our country is full of sound and colour of. "College English Curriculum Requirements (for Trial Implementation) as a programmatic document for the educational reform plays a very important guiding role, which emphasizes that the goal of College English teaching is to cultivate students' comprehensive ability to use English to enhance their ability of autonomous learning" (Department of higher education, 2004:1) also pointed out that College English teaching model "should be used advanced information technology, to promote the English Teaching of computer and network in the personalized learning and autonomous learning in English teaching based on the direction of development" (Department of higher education, thus 2004:), computer network of College English teaching and the students' autonomous learning of the two aspects of $u$ has become the focus of College English Teaching Reform for the the long-term adaptation in the traditional teaching methods of teachers and students are based on a serious challenge. As a pilot Institute of Ministry of education mode of College English teaching reform is to effectively carry out the pilot work, we think first of all it is necessary to straighten out the elements related to in the environment of computer network teaching students' autonomous learning involved, and then starting from the actual situation of teaching resources of the Southeast University, the according to the related teaching theory and teaching practice of students under the computer network environment of autonomous learning of various feedback information, based on the new teaching environment of teaching activities to make corresponding design, modification and practice[1].

\section{Independent learning related factors}

In the definition of autonomous learning, different theories have different views, has been unable to reach consensus. As Hofec (1981), pointed out that autonomy is the self control ability of learning, including learning goals, to determine the learning content and progress, choose their learning method and the control process of acquisition and self-evaluation, define the main concern is students' self management capability and organization to force uLittle (1991), this definition has made an additional, he from the perspective of cognitive psychology to autonomous learning 
described, that autonomy is first of all to learn how it is organized. Benson (1996) in the absorption of the advantages of the two methods based on the proposed his own point of view, that autonomy in language learning is by three levels of self control, namely, a learning management, cognitive process and learning environment u Wen Qiufang (996) in the English learning strategy "of a book put forward the strategy system including two sub system of management system and the learning system, for Chinese learning the language of the law are discussed. She pointed out that influence English learning strategy system of factors including learning factors and environmental factors, learning factors, including intelligence, language, gender, motivation, effort, cognitive, emotional characteristics; environmental factors including learning conditions, teaching environment and learning tasks. Comprehensive analysis of each said, combined with the characteristics of foreign language teaching, we believe that English autonomous learning elements should include the following factors, learning motivation, learning methods, learning time, reflective learning, learning plan, learning outcomes, learning content and learning situation etc. $u$ the first six elements belonging to the learner internal factors, after two elements belong to the external factors.

\section{Correlation principle}

The introduction points out the necessity of computer network environment to study autonomous learning. At the same time, balancing the elements of autonomous learning and then relying on what the theory, principle, to conduct research and construction theory and the College English curriculum requirements "make this a very good explanation.

Constructivism includes cognitive constructivism and social constructivism. Doctrine of the pioneer of Piaget and social constructivism founder of Vygotsky and cognitive construction are the same attention to the cognitive process of learning, to learning as a course of learners' active construction of the knowledge rather than by others "to give" and spontaneous acceptance and use of the process. "The source of cognitive structure is the interaction of the host and the object, and the two-way structure is contained in the interaction:

Environmental information internalized to form cognitive structure (internalization of construction at the same time, has formed or is formed of cognitive structure movement in the environment and transform the environment (and construction) '(since Lixia, 2004:66) for the learning process, the theory of Constructivism also made own interpretation, to recognize that for the mainly includes three aspects, that is, "learning is a cognitive structure construction process"; "learning is a negotiation process, learning is a real environment experience" (turn self Lixia, 2004:6 constructivism also stressed student-centered, emphasizing learning autonomy and personalized. And under the computer network environment, the research on autonomous learning and traditional classroom environment of independent study of major difference lies in the construction of the external environment of different, and therefore should be based on constructivism theory as a guide, and actively build various external structure of autonomous learning of the students under the computer network environment, to promote the construction of the student's knowledge of the internal[2].

The College English curriculum requirements "(for Trial Implementation) fully affirmed the positive role of multimedia and network technology in the new teaching mode, and points out the principle of" the new teaching model should reflect the combination of English Teaching of practical, knowledge and interest, should fully mobilize the enthusiasm of both teachers and students, in particular to establish the dominant position of the students in the teaching process. The development of autonomous learning ability is an important sign of the success of the reform of the teaching model is the formation of students' individualized learning method and students. To effectively promote reform of teaching mode, we should strengthen students' learning English by computer course or obtain the proportion of credits. Suggested that students in the computer learning received proportion of credit should be English accounted for 30\% of the total credits of learning a 50\% "(Department of higher education, 2004:-7), we can see that the new teaching mode of teaching principles, teaching methods and teaching target are clearly defined, in actual operation shall take full account of these principles, method and target. 


\section{Study on the practice of autonomous learning elements in computer network environment}

The practice and research of autonomous learning elements on the computer network environment, mainly on learning motivation, learning method, learning time, reflective learning, learning plan, learning content, learning environment and learning results. Research for the same test object in different periods of vertical comparison, at the same time, to ensure the relative and can be referenced, set up corresponding referents were studied and compared to ensure research in different research object of horizontal comparison. So we choose the independent learning in the traditional classroom environment can be the reference of the study. In order to ensure the effectiveness of the study, the selection of reference materials (hereinafter referred to as control group) and the control group is generally similar to the initial level.

4.1.1 experimental group and control group at the beginning of the experiment analysis of Freshmen of 2004 Grade Students in the experimental group and control group. The students in the experimental group for 6 classes, which strengthen the 90 class, English class of 98, 188. The control group of students for the English class 180 students.

4.1.2 experimental group and control group at the beginning of the experiment analysis of students grades we students of the college entrance examination scores and new placement test scores were paired samples t test, the experimental group 188 students, control group 180 students.

Results of college entrance examination. CLASS1 on behalf of the control group, CLASS2 on behalf of the experimental group "from the table shows" $=$ a $0.7 \wedge=0.485^{\wedge}$ value greater than 0.05 , the experimental group and control group, no significant difference in the college entrance examination results. At the same time the use of EXCEL for all the students' scores, we learned that the control group was 131.18, the experimental group was 131.33, the experimental group was slightly higher than the control group, but there was no significant difference between the control group and the control group.

Results of Freshmen's examination results. CLASS1 on behalf of the control group, CLASS2 on behalf of the experimental group $\mathrm{u}$ by the table, $\mathrm{t}=\mathrm{a} 1.3, \mathrm{p}=0.195, \mathrm{P}$ value is greater than 0.05 , the experimental group and control group, no significant difference in the college entrance examination results. At the same time, the use of EXCEL for all students' scores, we learned that the control group was 80.43 , the average of the experimental group was 80.68 , the difference between the experimental group and control group[3].

\subsection{3 summary}

From the beginning of state related information and learning achievement analysis shows that the experimental group and the control group in autonomous learning elements, including learning motivation, learning plan, learning method, reflective learning, learning time, learning achievement, etc. are similar $\mathrm{u} 4.2$ experimental process

The focus of this experiment is the comparative study of autonomous learning under the environment of computer network and the autonomous learning under the traditional teaching mode, in order to find out the relevant laws and problems and the corresponding countermeasures. The biggest difference between the two lies in the teaching mode, which is different from the external factors of students' autonomous learning. Because self does not necessarily mean completely independent, so we emphasize autonomous learning under the guidance of teachers, teachers should according to the constructivism and "College English curriculum requirements" principles and theories, and actively create different learning situations, stressed students according to the actual situation of the individual, self determined learning goals, choose learning methods, monitor learning process, and assess learning results. In a period of a year at the end of the experiment, and on students' autonomous learning intrinsic factors and academic performance analysis and comparison study under the premise of changes in external factors of autonomous learning, students' internal factors of the variation.

\subsection{1 computer network environment of the experimental instructions}

The model of the textbook for Higher Education Press published "Experiencing English" series of textbooks (comprehensive, expansion, listening and speaking course) and supporting the network course and listening and speaking course learning system software[4]. 
Teaching mode: big / small class teaching and Extracurricular Autonomous Learning and the second classroom, 4 hours per week of classroom teaching, every 4 to 6 hours of extra-curricular machine and the spare time to carry out the second classroom activities u classroom teaching: 4 hours per week mainly completes "Experiencing English" integrated teaching process and related content of learning. Large class teaching, by the students by visiting the campus net network tutorial courseware from the main completed a comprehensive tutorial learning; teaching in small classes, respectively, and network related tutorial practicing spoken English and writing for multimedia translation teaching, play the advantages of traditional classroom; extracurricular machine: every week for students provides 4 to 6 hours of extra computer time, and arrange for English major graduate students in extra-curricular computer teaching counseling and guidance, by the students autonomous learning "College Experiencing English listening and speaking course supporting software, and comprehensive tutorial tutorials network outside of the content. Second classroom activities form: every week to invite foreign teachers to organize lectures for students to discuss the British and American culture, for the students to show the original film. Each month to carry out a large-scale activities, such as the British and American cultural knowledge contest, written in English newspapers, magazines, etc., so that students through the completion of the task to enhance the actual use of language skills, cooperative learning ability.

The experimental description of the traditional classroom environment of 4.2 .2

The teaching materials used in this model are the series of textbooks for Higher Education Publishing House, which includes comprehensive, extended and listening and speaking course.

Teaching mode: classroom teaching + second class, that is, 4 hours per week classroom teaching and extracurricular time to carry out the second classroom. Classroom teaching: 4 hours a week of classroom teaching mainly to complete the "college experience English" integrated course and listening and speaking course, students in the teacher's requirements, the completion of the class in the classroom and listening, speaking training. The teacher is mainly in the classroom. Classroom teaching is mainly based on Teachers' teaching, oral activities require students to participate actively, emphasizing their learning subjectivity[5]. Second classroom activities are similar to the computer network environment.

\section{Conclusion}

Research on computer network environment is a hot topic in foreign language teaching. The pilot work of teaching reform based on the Southeast University, elements of student computer network environment of autonomous learning in english. Integrated the various long established various elements of autonomous learning and to classify the elements. In constructed under the guidance of theory and the College English curriculum requirements ", various external factors on learner autonomy to actively construct study under different external conditions, learners' autonomous learning internal factors to construct the internal rule. Comparative research of independent learning under the environment of computer network and traditional teaching environment, draws the following conclusion: positively construct autonomous learning of external factors such as learning content and learning situation can have a positive role in promoting the internal factors of autonomous learning. By emphasizing the independent study and apply their knowledge, strengthen the second class to first class washback, internal factors of the two types of learning environment of students' autonomous learning progress. In addition, the teaching mode based on computer networks than in traditional teaching emphasizes students' Independent Learning under the guidance teachers, computer learning, and fully guarantee the student's independent study time, and autonomous learning the internal factors of the change is more obvious.Discussion on autonomous learning time influence the learning effect, to carry out the traditional mode of strengthening methods of autonomous learning, give full play to the advantages of traditional classroom, will be the future work for further study.. 


\section{References}

[1] HolecH.Aw/onomyinForeignLangLearning[M].Oxford: Pergamon1981.

[2] LiltleD.LearningAutonomy1:Definitions, IssusandProblems[M].Dublin: Authentic1991.

[3] BensonP. Concepts of Autonomy in Language Learning[A]. R.Pemberton(ed.) Taking Control: Autonomy in Language Learn-ing[C]. HongKong: HongKongLniversitvPress1996.

[4] Department of higher education of the Ministry of education. College English Curriculum Requirements (for Trial Implementation) M]. Beijing: Higher Education Press, 2004:8.

[5] Li Xia. Based on the constructivism theory to design the College English Network Courseware [J]. China audio visual education, 2004 (10). 